\title{
The Recent Research and Care of Benign Breast Fibroadenoma: Review Article
}

\author{
Abhinandan Gupta*, Hong Zhang, Jingbai Huang \\ Department of Medical Imaging and Nuclear Medicine, The First Affiliated Hospital of Yangtze University, Clinical Medical \\ College, Yangtze University, Jingzhou, China \\ Email: ^abhinandan7400@gmail.com
}

How to cite this paper: Gupta, A., Zhang, H. and Huang, J.B. (2019) The Recent Research and Care of Benign Breast Fibroadenoma: Review Article. Yangtze Medicine, 3, 135-141.

https://doi.org/10.4236/ym.2019.32013

Received: January 22, 2019

Accepted: March 19, 2019

Published: March 22, 2019

Copyright (๑) 2019 by author(s) and Scientific Research Publishing Inc. This work is licensed under the Creative Commons Attribution International License (CC BY 4.0).

http://creativecommons.org/licenses/by/4.0/

\begin{abstract}
Fibroadenomas are the most common lumps found in adolescence girls. They usually occur under the influence of hormonal changes that the girls undergo at the time of puberty and they happen due to overgrowth of glandular tissue in the breast. Ultrasonography is the best diagnosis for fibroadenoma. There is no medical treatment for fibroadenoma except surgical excision and a new method recently comes out-vacuum assisted fibroadenomas resection.
\end{abstract}

\section{Keywords}

Fibroadenoma, Ultrasound, Adolescence Girls, Glandular Tissue, Submammary Incision, Periareolar Incision

\section{Introduction}

Fibroadenoma "fibro" means the stromal tissue, "adenoma" means the glandular structural in epithelial tissue and "oma" simply means tumor [1]. So, of all the lump and bumps that we find in the breast, fibroadenoma is one of the most common [2]. Its peak age in Caucasian woman is in their twenties. Among African, American, Hispanic and other women of color [3] [4], it can actually start in the later part of the teen years. The fibroadenomas arise out of what is called the terminal ductal lobular units, and the same place interesting that breast cancer arises; it probably arises because of a lot of unopposed estrogen. So, when you think about the development of young woman there is a lot of unopposed estrogen as breasts are growing; things of this sort are happening, and so that unopposed estrogen is a cause of the factor [3]. They usually present as simple, movable, painless, smooth, well defined lumps. They can be present in one breast or both the breasts. They can be single or multiple also. Majority of the time they remain stable in size; fibroadenoma does not really increase or de- 
crease. However a few may reduce over time, once the hormonal influence wears off. So, this is important in such a case, diagnosis in a young girl is obviously by the help of ultrasonography [5] [6]. There is a new method that has recently come out into medical practice which is vacuum assisted fibroadenomas resection. This is done by specialized equipment known as VAC machine.

\section{Discussion}

Fibroadenoma is the most common benign tumor of the female breast [1] [7]. So fibroadenoma contains mixture of stromal and epithelial tissue. To make it simpler, in fibroadenoma there are epithelial cells arranged in a fibrous stroma. Fibroadenoma gradually grows up to two to three centimeter in size.

In this picture shows the anatomy of the female breast (Figure 1). you can see the skin and then we have a darker circle of skin known as the areola this contains glands that help lubricate the nipple during breastfeeding and then we have the nipple in the middle if we can look at a cross section of the breasts we can see these round or oval shape lobes there is actually three layers to the breast the first layer is the subcutaneous layer which would contain the skin the subcutaneous fat and then we have the mammary layer which is these lobes normal breast contains 15 to 20 lobes within these lobes are smaller what's called lobules and if we were to take a look inside lobules we would see clusters of cells and these cells are called somatic cells. Somatic cells are epithelial tissue and they produce the milk of the human breast. These melts are then transported through these small ducts which will then converge into larger ducts more centrally. This is the single lobe (blue arrow) and these is smaller structure are lobules (black arrow). Fibroadenoma is an average of a normal development of single lobules.

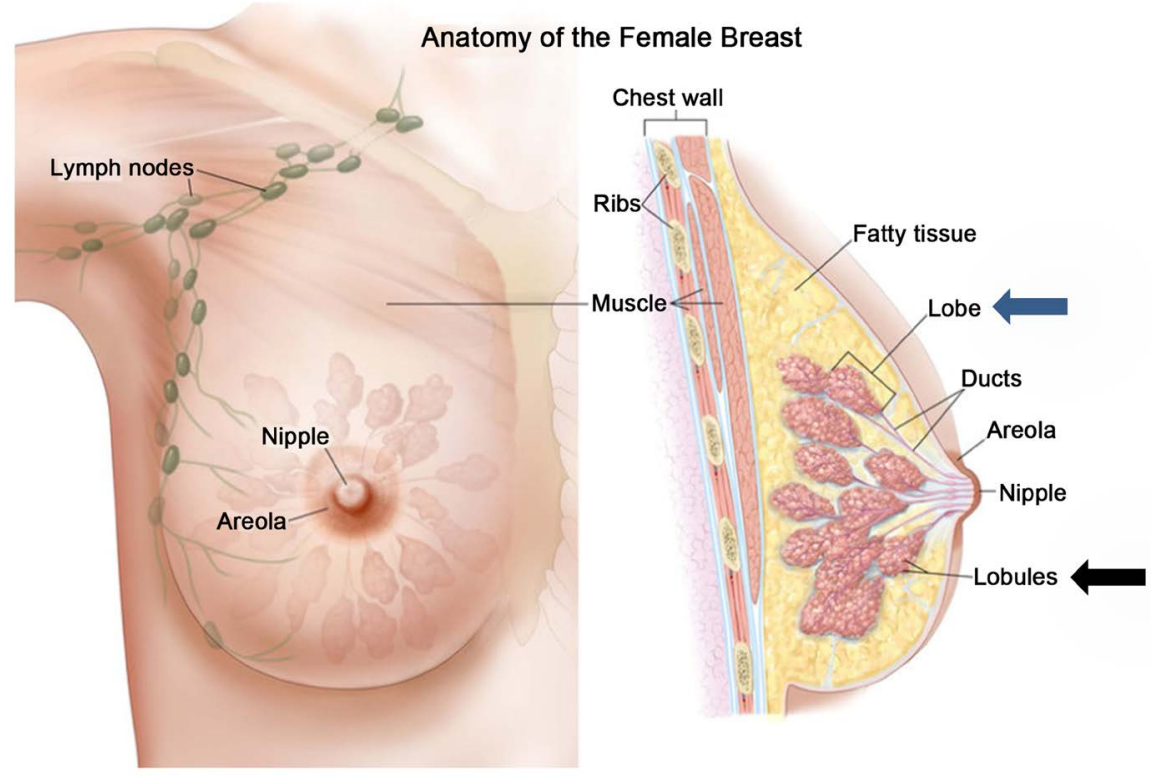

Figure 1. Anatomy of the female breast. 
This is the normal lobules (black arrow) and this is the fibroadenoma (red arrow) (Figure 2). Fibroadenoma is hyperplasia of single lobules. Let's talk about types of fibroadenoma they are 2 types: 1) Intracanalicular type (less fibrosis) and 2) Pericanalicular type (more fibrosis) [8]. Giant fibroadenoma: they are basically occurring in during puberty and they are greater than $5 \mathrm{~cm}$ in diameter. They are rapidly growing but they are clinically similar to smaller fibroadenoma. So the treatment remains same [9].

Histology of fibroadenoma as we discussed early depending on histological fibroadenoma can be divided into intracanalicular type and pericanalicular type (Figure 3). In this intracanalicular type of fibroadenoma, mainly cellular and less fiborsis and stroma with distorted duct [8]. In this pericanalicuar type of fibroadenoma, its mainly fibrous there is more fibrosis and stroma with the normal duct. In this we can see normal architecture of duct is maintained. Clinical features of fibroadenoma it usually occurs in young women between 15 to 30 years of the age. The peak in incidence is around 20 years of age. Mostly Patient with painless lump. On examination, the lump it is smooth, round bordered [9]. It is firm to hard in consistency. Remember a fibroadenoma as free movement within the breast tissue. So, it is also called "breast mouse".

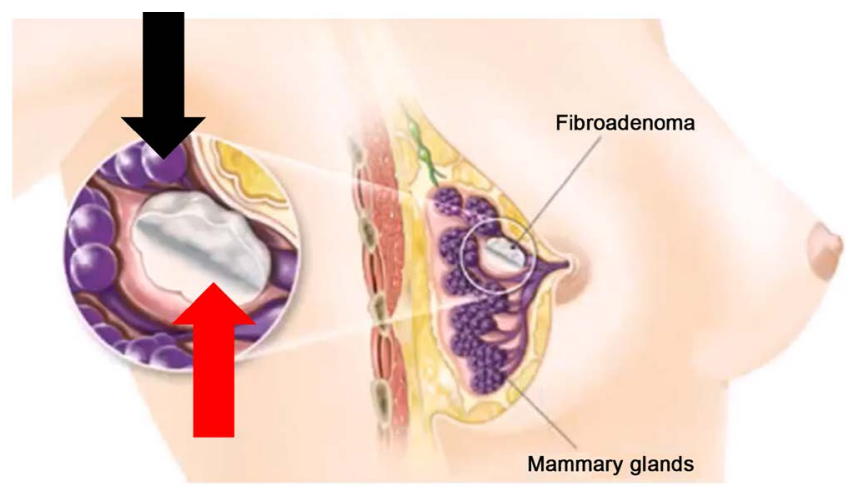

Figure 2. Normal lobule and fibroadenoma.

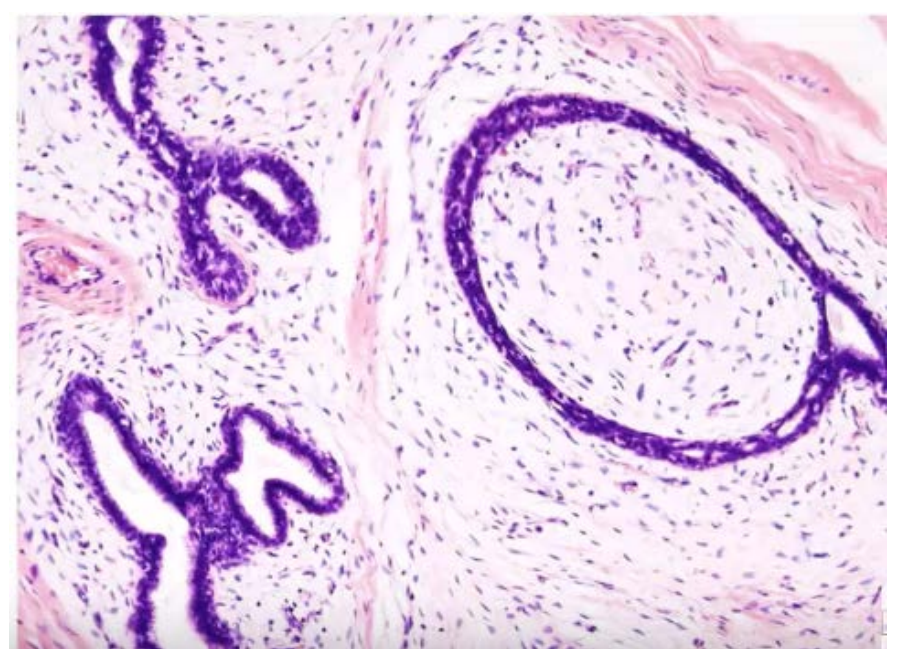

Figure 3. Histological fibroadenoma of intracanalicular type and pericanalicular type. 


\section{Investigation}

1) Mammography can be done (its well localized smooth regular shadow) because we would like to rule out any can cancerous lumps or not [10]. 2) FNAC (Fine Needle Aspiration Cytology) can be done to differentiated malignancy [11]. 3) Ultrasound can be done (to confirm Solid nature). Ultrasounds can diagnosis the fibroadenoma perfectly. In those cases after the diagnosis is confirmed then the treatment depends on the size of the fibroadenoma. Whether it is causing any symptom or whether there are any other problems because of fibroadenoma [11].

\section{Treatment}

There is no medical treatment for the fibroadenoma. There are no medicines to decrease lumps specifically, they may however as I mentioned earlier reduce on their own also. So the most important things to do are a keep these fibroadenoma under observation and follow up. The patients are told to come after 3 to 6 month. We repeat the sonography to see whether the lumps are increase or stable in size. If they are stable nothing more need to be done, they can be kept under follow-up every six months and if they are increasing in size then we need to do something about it, maybe a surgical excision. Fibroadenomas are surrounding by a well marked capsule so they can be enucleated (cosmetically appropriate incision). Excision of the lump is indicated in case of specious cytology is when the fibroadenoma become very large or when the patient herself wants to lump removes.

In case of intracanalicular type can be given submammary incision. In case of pericanalicular type periareolar incision can be given (Figure 4). Remember fibroadenoma did not operate always. In case of small fibroadenoma with a single, and in patient how are less than 30 year old, Fibroadenoma can be left alone with the regular follow up with ultrasound at 6-month interval.

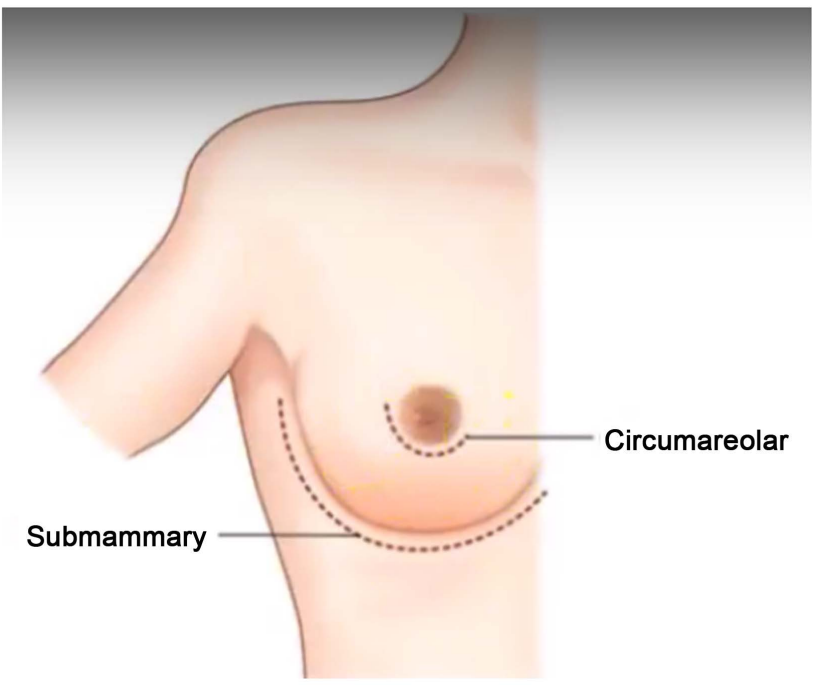

Figure 4. Submammary incision and periareolar incision. 
However surgical excision is not required in all the cases. It is required only in three conditions, 1) If the fibroadenomas is increasing in size. 2) If it is becoming painful for the patient. 3) If there is any confusion in diagnosis between fibroadenoma and may other condition [12]. Then it is always better to take the lumps out and there is a new method that has recently come out into medical practice that is vacuum assisted fibroadenomas resection [13]. This is done by specialized equipment known as VAC machine. This is a needle attached to suction tubing and what we do is give a local anesthesia procedure, it is an OPD procedure which takes about 15 to 20 minutes. Patient is awake and very comfortable during the procedure, so local anesthesia is given to make the area numb. A small cut of about 3 millimeter is made into the skin and this special needle introduced to the skin, goes to the area of fibroadenomas. The procedure is done under ultrasound guidance, so under the ultrasound we take the needle to the fibroadenomas and then we start resecting it. So, the needle inside it cut the tissue, it's rotates and it sucks out the small bits of a fibroadenomas into the suction machine. And the whole tissue is gradually taken out like that, through a hardly $3 \mathrm{~mm}$ incision. This is a very safe and simple procedure only risk of bleeding and that we take care of it, a good compression of about 10 minutes will takes care of all bleeding and the tissue that is resected is sent for histopathological correlation and nothing more is really needed after that. So this is a new method and however it is not suitable for all the cases, only fibroadenoma that are smaller than 2 centimeter and no very close to the skin of the chest wall. These are the one which are suitable for VAC resection. And it can be done for these patients [14]. so as I said that the most common motility for treatment of fibroadenoma is observation and follow-up and surgical resection and a VAC resection is required only for the very few people in which fibroadenomas are increasing and in painful.

\section{Complication}

Fibroadenoma is benign tumor but rarely complex fibroadenoma which contains cyst sclerosing adenosis and calcification can turn in malignant. It's chance of it turning into cancer tumors very low about $0.2 \%$ to $0.1 \%$ [15].

\section{Differential Diagnosis}

Breast cyst: -fluid filled lumps; Breast carcinoma: -very little risk of progressing to breast carcinoma; Phyllodes tumor: -hypercellularstroma in prominent, stromal overgrowth; Breast lymphoma: -rarely malignant; Metastasis to the breast from another primary site [16].

\section{Conclusion}

Fibroadenomas are the most common lumps found in adolescence girls. They usually occur under the influence of hormonal changes that the girls undergo at the time of puberty and they happen due to overgrowth of glandular tissue in the 
breast. With the help of ultrasound we can diagnose. There are no medicines to decrease lumps except surgical excision and there is a new technique recently coming out-vacuum assisted fibroadenomas resection. Fibroadenoma is benign tumor but rarely malignant.

\section{Acknowledgements}

This work was supported by grants from the National Natural Science Foundation of China (31700736), Hubei Province Health and Family Planning Scientific Research Project (WJ2016Y07), Hubei Province Scientific and Technological Research Project (Q20171306) and the College Students Innovative Entrepreneurial Training Program in Yangtze University (2018184).

\section{Conflicts of Interest}

The authors declare no conflicts of interest.

\section{References}

[1] Borecky, N. and Rickard, M. (2008) Preoperative Diagnosis of Carcinoma within Fibroadenoma on Screening Mammograms. Journal of Medical Imaging and Radiation Oncology, 52, 64-67. https://doi.org/10.1111/j.1440-1673.2007.01913.x

[2] Sosin, M. and Feldman, E. (2013) Giant Juvenile Fibroadenoma: A Case and Review of Novel Modalities in Treatment. Breast Disease, 34, 35-38. https://doi.org/10.3233/BD-130342

[3] Song, B.S., et al. (2014) Giant Juvenile Fibroadenoma of the Breast: A Case Report and Brief Literature Review. Annals of Pediatric Endocrinology \& Metabolism, 19, 45. https://doi.org/10.6065/apem.2014.19.1.45

[4] Thoma, A., et al. (2007) A Prospective Study of Patients Undergoing Breast Reduction Surgery: Health-Related Quality of Life and Clinical Outcomes. Plastic and Reconstructive Surgery, 120, 13-26. https://doi.org/10.1097/01.prs.0000263370.94191.90

[5] Fornage, B.D., Lorigan, J.G. and Andry, E. (1989) Fibroadenoma of the Breast: Sonographic Appearance. Radiology, 172, 671-675. https://doi.org/10.1148/radiology.172.3.2549564

[6] Rothschild, P., Jackson, V.P. and Holden, R.W. (1985) The Spectrum of Sonographic Findings in Fibroadenoma of the Breast. Investigative Radiology, 20, S10. https://doi.org/10.1097/00004424-198509000-00067

[7] Houssami, N., Cheung, M.N. and Dixon, J.M. (2001) Fibroadenoma of the Breast. The Medical Journal of Australia, 174, 185-188.

[8] NIE, Y.T., et al. (2015) Differentiating the Two Main Histologic Categories of Fibroadenoma Tissue from Normal Breast Tissue by Using Multiphoton Microscopy. Journal of Microscopy, 258, 79-85. https://doi.org/10.1111/jmi.12219

[9] Ajmal, M. and Van Fossen, K. (2018) Breast Fibroadenoma, in StatPearls. StatPearls Publishing, Treasure Island.

[10] Prasad, S.N. and Houserkova, D. (2007) A Comparison of Mammography and Ultrasonography in the Evaluation of Breast Masses. Biomedical Papers, 151, 315-322. ttps://doi.org/10.5507/bp.2007.054

[11] Pillay, S., Cheddie, S. and Moodley, Y. (2018) Fibroadenoma of the Breast in a 
South African Population-A Pilot Study of the Diagnostic Accuracy of Fine Needle Aspirate Cytology and Breast Ultrasonography. African Health Sciences, 18, 273-280. https://doi.org/10.4314/ahs.v18i2.11

[12] Javed, A., et al. (2018) Intermediate and Long-Term Outcomes of Fibroadenoma Excision in Adolescent and Young Adult Patients. The Breast Journal, 25, 91-95. https://doi.org/10.1111/tbj.13159

[13] La Perna, L., et al. (2000) Ultrasound-Guided Thrombin Injection for the Treatment of Postcatheterization Pseudoaneurysms. Circulation, 102, 2391-2395. https://doi.org/10.1161/01.CIR.102.19.2391

[14] Grady, I., Gorsuch, H. and Wilburn-Bailey, S. (2008) Long-Term Outcomeof Benign Fibroadenomas Treated by Ultrasound-Guided Percutaneous Excision. The Breast Journal, 14, 275-278. https://doi.org/10.1111/j.1524-4741.2008.00574.x

[15] Wu, Y.-T., et al. (2014) Breast Cancer Arising within Fibroadenoma: Collective Analysis of Case Reports in the Literature and Hints on Treatment Policy. World Journal of Surgical Oncology, 12, 335. https://doi.org/10.1186/1477-7819-12-335

[16] Chung, E.M., et al. (2009) Breast Masses in Children and Adolescents: Radiologic-Pathologic Correlation. RadioGraphics, 29, 907-931.

https://doi.org/10.1148/rg.293095010 